\title{
Biologic Effect of Low-Intensity Electromagnetic Radiation on Myocardium in Experimental Ischemia
}

\author{
DOI: 10.17691/stm2015.7.2.06
}

Received May 30, 2014

S.L. Malinovskaya, DSc, Professor, Department of Medical Physics and Informatics;

A.P. Bavrina, PhD, Associate Professor, Department of Medical Physics and Informatics;

T.I. Solovyova, PhD, Senior Researcher, Central Scientific Research Laboratory;

M.V. Rakhcheyeva, Researcher, Electron Microscopy Unit, Central Scientific Research Laboratory;

E.I. Yakovleva, PhD, Senior Researcher, Electron Microscopy Unit,

Central Scientific Research Laboratory;

V.A. Monich, DSc, Professor, Head of the Department of Medical Physics and Informatics

Nizhny Novgorod State Medical Academy, 10/1 Minin and Pozharsky Square, Nizhny Novgorod, 603005,

Russian Federation

The aim of the investigation was to study modification of lipid peroxidation level and myocardium microstructure in rats exposed to lowintensity laser radiation (LILR) as compared to the effects caused by broadband red light (BBRL).

Materials and Methods. The research was performed on 91 white outbred male rats weighing 250 to $280 \mathrm{~g}$. The experimental animals were divided in two test groups and two control ones: control group $1(n=23)$, spurious irradiation without ischemia; control group 2 ( $n=22)$, ischemia + spurious irradiation; test group $1(n=21)$, ischemia + exposure to LILR; test group $2(n=25)$, ischemia + exposure to BBRL. Cardiac ischemia was modelled by blocking the rats' left coronary artery in situ for $5 \mathrm{~min}$. In the test groups light irradiation was performed during $10 \mathrm{~min}$ immediately after the ligature removal. Helium neon laser LG-13 and self-developed luminescent fiber optic apparatus were used as light sources.

Results and Discussion. Exposure of myocardium both to laser radiation and broadband light decreased the peroxidation level in the myocardium tissues. The exceptions were observed in content of trienoic conjugates in the group exposed to laser light. A more effective decrease in the level of primary peroxidation products was found in the group irradiated by BBRL.

Electron microscopic study of the myocardium tissues microstructure demonstrated a reduced condition of cardiomyocytes exposed to LILR; presence of sarcomeres dilatation, hypertrophic mitochondria and their swelling; dialation of sarcoplasmic reticulum; insignificant quantity of granule cells. At the same time, in the samples exposed to BBRL we observed no signs of sarcoplasm clearing; mitochondria were slightly swollen with preserved cristae, Golgi complex was well-marked; granule cells content in the sarcoplasm was greater than in the control group with ischemia and spurious irradiation and much greater than in the group exposed to LILR. The dispersed chromatin nuclei contained 1 or 2 nucleoli.

Conclusion. The study of cardiomyocyte subcellular structure after oxidative stress induced by ischemia and consequent reperfusion revealed adaptive changes only in the species exposed to BBRL (nuclei activation: euchromatin, nucleoli availability, mitochondria structure preservation and significant content of granule cells).

The observed difference in the microstructure of the heart muscle cells in two test groups clearly demonstrates the dissimilarity in photobiomodification processes caused by laser radiation as compared to broadband red light (of the similar intensity in the light spot zone and the spectral maximum near the laser radiation line).

The resulting data enable us to speak about the possibility of using low-intensity BBRL irradiation of the heart as an effective method for recovery of the heart muscle after oxidative stress caused by ischemia and reperfusion and restoration of the hemodynamic characteristics of the coronary system.

Key words: low-intensity laser radiation; broadband red light; myocardium.

Comparison of the effects caused by low-intensity laser radiation (LILR) and broadband red light (BBRL) by using the well-documented technology of electronic microscopy solve one of the principle problems of photobiology and laser medicine concerning the importance of radiation coherence and monochromasy for the rate of response of living tissues to low - power light exposure. The study aims at creating the technology of heart muscle tissue regeneration after oxidative stress caused by ischemia and myocardium reperfusion.
The aim of the investigation was to study the difference in lipid peroxidation levels and myocardium microstructure in rats exposed to low-intensity laser radiation with respect to irradiation of the animals by broadband red light.

Materials and Methods. Cardiac ischemia simulation was carried out in situ by blocking the rats' left coronary artery for $5 \mathrm{~min}$. After tracheotomy and thoracotomy the animal was connected to an artificial lung ventilation apparatus. A ligature blocked blood flow through the left

For contacts: Monich Viktor Anatolyevich, e-mail: vam@gma.nnov.ru 
branch of the coronary artery under the left auricle. As a result, acute myocardium ischemia developed.

Direct LILR or BBRL irradiation of the sinus node was started just after the ligature removal and continued for $10 \mathrm{~min}$. LG-13 helium neon laser (Russia) was used as a source of LILR and a self-developed luminescent fiber optic apparatus generated BBRL [1]. The maximum wavelength in the luminescent radiation spectrum was $640 \mathrm{~nm}$, the width of the radiation spectrum was $70 \mathrm{~nm}$. The light spot had the diameter of $3 \mathrm{~mm}$. The radiation intensity in the light spot area was $5 \mathrm{~mW} / \mathrm{cm}^{2}$.

The level of lipid peroxidation processes was assessed by contents of molecular products of peroxidation in the myocardium tissues: dienoic conjugates (DC), trienoic conjugates (TC) and malondialdehyde (MDA) [2]. The rate of enzymatic antioxidant protection system of cells was assessed by superoxide dismutase (SOD) activity [3].

Tissue samples for electron microscopy investigation were taken from the left ventricle in the area of papillary muscles. The samples were prepared according to the methods described earlier [2]. Electron microscope Morgagni 268D (FEl, USA) was used for the investigation. Morphometric measuring was done using AnalySIS software.

The study was performed on white outbred male rats weighing $250-280 \mathrm{~g}$ subsisted on the standard vivarium ration. The ethical principles established by the European Convention for the Protection of Vertebrate Animals Used for Experimental and Other Scientific Purposes (adopted in Strasburg on March, 18, 1986, confirmed in Strasburg on June, 15, 2006) and approved by the Ethics Committee of Nizhny Novgorod State Medical Academy were strictly followed in the study.

The experimental animals (91 rats) were divided into two test groups and two control ones: control group 1 $(n=23)$, spurious irradiation without ischemia; control group $2(n=22)$, ischemia + spurious irradiation; test group $1(n=21)$, ischemia + exposure to LILR and test group $2(n=25)$ ischemia + exposure to BBRL. The significance of differences between the tested groups of animals was determined by using Student's t-test with Bonferroni correction for multiple comparisons [4].

Results and Discussion. Both laser and broadband light irradiation of myocardium decreased the peroxidation level in the myocardium tissues (Table 1). The exception was observed for TC in the group exposed to laser light.

The content of primary molecular products of peroxidation decreased in 4 samples of the group exposed to BBRL by $26 \%$ and in the samples exposed to LILR by $16 \%$.

Decrease in the level of molecular peroxidation products can be caused by photochemical processes due to activity changes in superoxide dismutase and other enzymes having absorption band in the red and near infrared spectral band. Superoxide dismutase is one of the crucial elements of enzymatic system for anti-peroxide cell protection and has absorption band in the red spectral region [5]. The results obtained by this research showed, that BBRL increases superoxide dismutase activity in the myocardium tissues, whereas laser radiation causes an adverse effect (See Table 1).

The electron microscopy investigation demonstrated that, cardiomyocytes (CMC) in the samples of control group 2 were in a reduced condition with segments of excess reduction as well as dilatation in the subsarcolemmal zone. Sarcoplasmic reticulum (SPR) dilatation (Table 2) was observed in CMC, flaked osmiophil material was found in their lumen (See Figure (b)). The most part of cellular nuclei did not contain nucleoli, had minor invagination and chromatin margination. In a number of $\mathrm{CMC}$ the nuclei were located in the subsarcolemmal zone. The sarcolemma was swollen, with foci of destruction. Hyperplasia of mitochondria, their swelling, matrix clearing, cristae

T a b le 1

\begin{tabular}{|c|c|c|c|c|}
\hline Experiment conditions & $\begin{array}{c}\text { SOD activity } \\
\text { (unit of activity/g } \\
\text { tissue.per min) }\end{array}$ & $\begin{array}{l}\text { DC (optical } \\
\text { density/mg } \\
\text { of total lipid) }\end{array}$ & $\begin{array}{c}\text { TC (optical } \\
\text { density/mg } \\
\text { of total lipid) }\end{array}$ & $\begin{array}{l}\text { MDA (optical } \\
\text { density/mg } \\
\text { of total lipid) }\end{array}$ \\
\hline $\begin{array}{l}\text { Control group } 1 \text { (spurious } \\
\text { irradiation without ischemia) }\end{array}$ & $21.86 \pm 0.71$ & $0.49 \pm 0.05$ & $0.19 \pm 0.03$ & $2.40 \pm 0.12$ \\
\hline $\begin{array}{l}\text { Control group } 2 \text { (ischemia + } \\
\text { spurious irradiation) }\end{array}$ & $16.75 \pm 0.93$ & $0.58 \pm 0.08$ & $0.18 \pm 0.03$ & $3.09 \pm 0.13$ \\
\hline $\begin{array}{l}\text { Test group } 1 \text { (ischemia + exposure } \\
\text { to LILR) }\end{array}$ & $13.06 \pm 0.81^{*}$ & $0.49 \pm 0.04$ & $0.21 \pm 0.03$ & $2.43 \pm 0.09$ \\
\hline $\begin{array}{l}\text { Test group } 2 \text { (ischemia + exposure } \\
\text { to } B B R L \text { ) }\end{array}$ & $18.96 \pm 0.62^{*}$ & $0.43 \pm 0.02^{*}$ & $0.17 \pm 0.02$ & $2.67 \pm 0.20^{*}$ \\
\hline
\end{tabular}

$\mathrm{N}$ o t e: * statistical significance of value differences with control group $2 ; \mathrm{p} \leqslant 0.05$. 
BIOMEDICAL INVESTIGATIONS

Table 2

Morphometric indices of post-ischemic myocardium in white rats

\begin{tabular}{lccc}
\hline \multicolumn{1}{c}{ Experiment conditions } & $\begin{array}{c}\text { Sarcomere } \\
\text { length }(\mu \mathrm{m})\end{array}$ & $\begin{array}{c}\text { Mitochondria } \\
\text { area }\left(\mu \mathrm{m}^{2}\right)\end{array}$ & $\begin{array}{c}\text { SPR area } \\
\left(\mu \mathrm{m}^{2}\right)\end{array}$ \\
\hline Control group 1 (spurious irradiation without ischemia) & $1.68 \pm 0.08$ & $0.49 \pm 0.06$ & $0.02+0.003$ \\
\hline Control group 2 (ischemia + spurious irradiation) & $1.64 \pm 0.08$ & $0.59 \pm 0.03^{+}$ & $0.05 \pm 0.01^{+}$ \\
\hline Test group 1 (ischemia + exposure to LILR) & $1.54 \pm 0.05^{+}$ & $0.82 \pm 0.03^{\star+}$ & $0.13 \pm 0.04^{\star+}$ \\
\hline Test group 2 (ischemia + exposure to BBRL) & $1.55 \pm 0.05^{+}$ & $0.63 \pm 0.02^{+}$ & $0.06 \pm 0.01^{+}$ \\
\hline
\end{tabular}

$\mathrm{N}$ o t e: * statistical significance of value differences with control group $2 ; p \leqslant 0.05 ;{ }^{+}$with the group of intact animals; $p=0.05$.
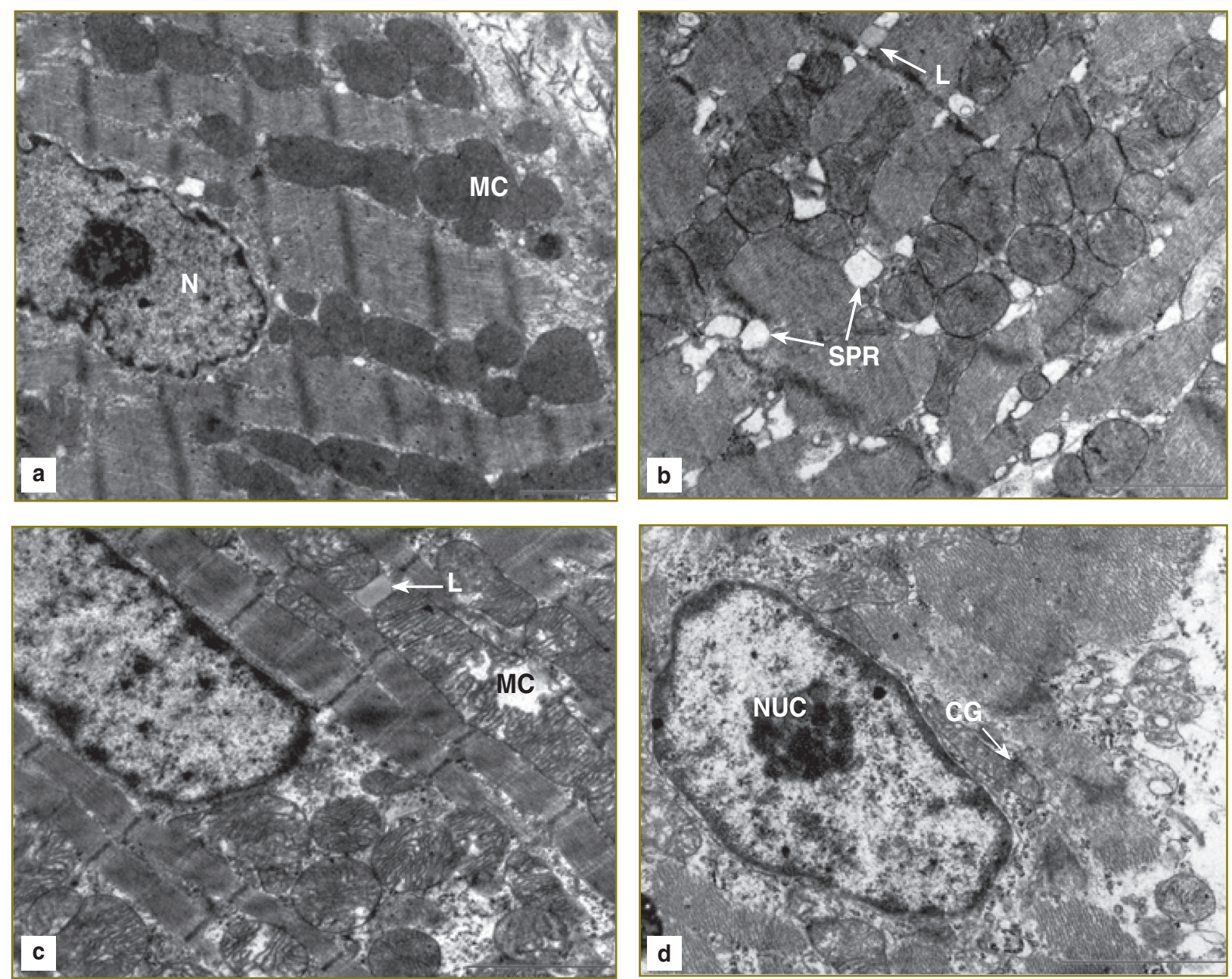

Cardiomyocytes ultrastructure in white rats: (a) after spurious irradiation without ischemia, $\times 8900$; (b) after spuriuos irradiation with ischemia, $\times 11000$; (c) after exposure to LILR with ischemia, $\times 11000$; (d) after exposure to BBRL with ischemia, $\times 14000$. N: nucleus, MC: mitochondria, L: lipid drop, SPR: sarcoplasmic reticulum, NUC: nucleolus, CG: cytogranules

destruction and disorientation can also be noted. External membrane alteration was revealed in some mitochondria. Lipid inclusions, secondary lysosomes and few granule cells were found in the sarcoplasm.
In the samples exposed to LILR cardiomyocytes were mainly in a reduced condition with segments of excess reduction. In some cases sarcomeres dilatation was revealed. Marked heterogeneity of mitochondria showed 
itself in the presence of both normal and hypertrophic forms (See Figure (c)). Mitochondria swelling, matrix clearing, cristae fragmentation were noted. The nuclei were with insignificantly clarified nucleoplasm and chromatin margination. In some CMC the nuclei were located at the cell periphery, SPR was dilated.

Clearing areas were observed in the sarcoplasm, in some cases diffuse intracellular edema, lipid inclusions, primary and secondary lysosomes were found. Granule cell content was inconsiderable.

In test group 2 (BBRL irradiation) samples the CMC sarcoplasm did not reveal clearing signs, mitochondria were slightly swollen with preserved cristae. The Golgi complex was well-marked and in separate cases hypertrophic. Granule cell content in the sarcoplasm was greater than in control group 2 and in test group 1 (See Figure (d)). Dispersed chromatin nuclei contained 1-2 nucleoli.

The study of CMC subcellular structure after oxidative stress caused by induced ischemia and consequent reperfusion revealed adaptive changes only in the species exposed to BBRL (nuclei activation: euchromatin, nucleoli availability, mitochondria structure preservation and significant content of granule cells).

The differences in the heart muscle cell microstructure in the two test groups clearly demonstrate peculiarities of the photobiomodification processes caused by laser radiation as compared to broadband red light (of similar light spot zone intensity and the spectral maximum near the laser radiation line). These peculiarities can be associated with several factors. Firstly, the results obtained in our study indicate differently directed photochemical effects of LILR and BBRL on SOD activity. We also suppose that there is a difference in the light impact of LILR and BBRL on cytochrome $\mathrm{C}$ oxidase (another complex protein having several chromophoric centers). The role of this enzyme as a primary molecular light acceptor has long been discussed in the literature [6]. The other important factor which can modify the processes in biological samples irradiated by low intensity light is LILR coherence [7, 81. Laser light interferes on optical heterogeneities and causes overirradiation of live tissues in the interference patterns with consequent local changes of $\mathrm{CMC}$ microstructure mentioned above.

One more factor explaining specific features of photobiomodification caused by LILR as compared to BBRL is photochemical effect of infrared light on cytochrome c oxidase - NO complex [9]. Nitrogen oxide migration causes a vasodilatory effect and is able to activate a sequence of microcirculation recovery processes: decrease of lipid peroxidation level in the myocardium tissues and recovery of the CMC microstructure. In this case it is important that the LILR spectrum is narrow and positioned beyond the infrared light band, whereas BBRL spectrum spreads up to the near infrared band. Low-intensity visible light is a crucial physical agent initiating cascades of photobiomodification processes.

Conclusion. BBRL enables to smooth the oxidative stress consequences in the heart muscle tissues, to improve the hemodynamic characteristics of the coronary system and finally to accelerate the recovery of the mechanical characteristics of the heart muscle after ischemia.

The results of this investigation show the efficacy of low-intensity broadband light irradiation of the heart after myocardium ischemia and perspectives of clinical application of BBRL.

Study Funding and Conflict of Interests. This study was not funded by any sources, and there is no topic specific conflict of interest related to the authors of this study.

\section{References}

1. Monich V.A., Monich E.A., Golikov V.M. Patent RF 25007201. 1994.

2. Men'shchikova E.B., Zenkov N.K., Lankin V.Z., Bondar' I.A., Trufakin V.A. Okislitel'nyy stress: patologicheskie sostoyaniya i zabolevaniya [Oxidative Stress: Pathoses and Diseases]. Novosibirsk: ARTA; 2008; 284 p.

3. Nishicimi M., Appaji Rao A., Yagi K. The occurrence of superoxide anion in the reaction of reduced phenazine methosulfate and molecular oxygen. Biochem Biophys Res Commun 1972; 146(2): 849-854, http://dx.doi.org/10.1016/ s0006-291x(72)80218-3.

4. Glants S. Mediko-biologicheskaya statistika [Biomedical statistics]. Moscow: Praktika; 1999; 459 p.

5. Vladimirov Yu.A., Osipov A.N., Klebanov G.I. Photobiological principles of therapeutic applications of laser radiation. Biochemistry (Moscow) 2004; 69(1): 81-90, http:// dx.doi.org/10.1023/b:biry.0000016356.93968.7e.

6. Karu T.Y. Universal'nyy kletochnyy mekhanizm lazernoy biostimulyatsii: fotoaktivatsiya fermenta dykhatel'noy tsepi tsitokhrom-s-oksidazy. V kn.: Sovremennye lazernoinformatsionnye $i$ lazernye tekhnologii [Universal cellular mechanism of laser biostimulation: photoactivation of respiratory chain enzyme cytochrome-c-oxidase. In: Modern laser and information technologies]. Pod red. Panchenko V.Ya., Golubeva V.S. [Panchenko V.Ya., Golubev V.S. (editors)]. Moscow: Interkontakt nauka; 2005; p. 131-143.

7. Bavrina A.P., Monich V.A., Malinovskaya S.L., Ermolaev V.S., Druzhinin E.A., Kuznetsov S.S. Correction of ionizing irradiation consequences with low-intensity light. Bulleten' eksperimental'noj biologii i mediciny 2013; 156(11): 608-610.

8. Bavrina A.P., Monich V.A., Malinovskaya S.L., Yakovleva E.I., Bugrova M.L., Lazukin V.F. Correction method for radiation-induced heart disease consequences by lowintensity electromagnetic radiation in experiment. Bulleten' eksperimental'noj biologii i mediciny 2015; 159(1): 115-119.

9. Zhang R., Mio Y., Pratt P.F., Lohr N., Warltier D.C., Whelan H.T., et al. Near infrared light protects cardiomyocytes from hypoxia and reoxygenation injury by a nitric oxide dependent mechanism. J Mol Cell Cardiol 2009 Jan; 46(1): 4-14, http://dx.doi.org/10.1016/j.yjmcc.2008.09.707. 